\title{
Water coning mechanism in Tarim fractured sandstone gas reservoirs
}

\author{
SHEN Wei-jun(沈伟军) $)^{1,2}$, LIU Xiao-hua(刘晓华) ${ }^{3}$, LI Xi-zhe(李熙喆) $)^{3}$, LU Jia-liang(陆家亮) ${ }^{3}$ \\ 1. Institute of Porous Flow and Fluid Mechanics, Chinese Academy of Sciences, Langfang 065007, China; \\ 2. University of Chinese Academy of Sciences, Beijing 100190, China; \\ 3. PetroChina Research Institute of Petroleum Exploration and Development-Langfang, Langfang 065007, China \\ (C) Central South University Press and Springer-Verlag Berlin Heidelberg 2015
}

\begin{abstract}
The problem of water coning into the Tarim fractured sandstone gas reservoirs becomes one of the major concerns in terms of productivity, increased operating costs and environmental effects. Water coning is a phenomenon caused by the imbalance between gravity and viscous forces around the completion interval. There are several controllable and uncontrollable parameters influencing this problem. In order to simulate the key parameters affecting the water coning phenomenon, a model was developed to represent a single well with an underlying aquifer using the fractured sandstone gas reservoir data of the A-Well in Dina gas fields. The parametric study was performed by varying six properties individually over a representative range. The results show that matrix permeability, well penetration (especially fracture permeability), vertical-to-horizontal permeability ratio, aquifer size and gas production rate have considerable effect on water coning in the fractured gas reservoirs. Thus, investigation of the effective parameters is necessary to understand the mechanism of water coning phenomenon. Simulation of the problem helps to optimize the conditions in which the breakthrough of water coning is delayed.
\end{abstract}

Key words: water coning; fractured gas reservoir; water cut; recovery factor

\section{Introduction}

The production of water from the fractured gas reservoirs is a common occurrence in gas fields. It may be attributed to some reasons such as the normal rise of water gas contact, water coning or water fingering. The water production increases the operating costs, and reduces the efficiency of the depletion mechanism and the overall recovery [1-4]. Among these mechanisms, water coning is a serious problem in many gas fields especially in some large Tarim fractured sandstone gas reservoirs where the gas zone has an underlying aquifer whether or not it serves as an active drive [5].

Since the first report related to water coning by MUSKAT and WYCOFF [6], many studies have been conducted on water coning in oil reservoirs. These studies focus on the development of correlation for breakthrough time, critical rate and water oil ratio following breakthrough [7-11]. Several general trends observed for the water-oil systems were relevant to the study of gas reservoirs. The correlations for water breakthrough were related to many parameters, such as perforation interval, production rate, aquifer size and reservoir permeability [12-14].

In contrast to oil reservoirs, relatively few studies have been reported about water coning in gas reservoirs especially in the fractured gas reservoirs, since water coning in gas well has been understood as a phenomenon similar to that in oil wells. KABIR [15] simulated the water coning phenomenon in a thin $(20 \mathrm{~m})$ gas reservoir, and the result showed that production rate could accelerate water coning while it did not impair the ultimate recovery. The experimental and numerical studies were reported by HAMON et al [16] on aspects of water production from the fractured Meillon field, and the result was that the low effective matrix permeabilities combined with wide fracture spacing resulted in little imbibition into the matrix. VAN GOLF and SONIER [17] identified the existence of high vertical permeability as a key parameter in influencing water coning problem in the fractured gas reservoirs. So far, the mechanism of water coning in fractured gas reservoirs was not exactly clear and to be further studied. Since the fractured sandstone gas reservoirs take a large proportion of proved and undeveloped reserves of Tarim basin [18], in order to efficiently and reasonably develop the gas fields, it is significantly necessary to study the mechanism of

\footnotetext{
Foundation item: Project(50150503-12) supported by National Science and Technology Major Program of the Ministry of Science and Technology of China; Project(2010E-2103) supported by Research on Key Technology in Tarim Oilfield Exploration and Development, China

Received date: 2013-09-06; Accepted date: 2013-12-27

Corresponding author: SHEN Wei-jun, PhD; Tel: +86-10-69213084; E-mail: wjshen763@gmail.com
} 
water coning phenomenon for improving recovery and development benefit.

The purpose of this work is to determine the most relevant parameters that contribute to water coning in fractured gas reservoirs. A model was developed to represent a single well with an underlying aquifer using the fractured sandstone gas reservoir data of the A-Well in Dina gas fields. The parametric study was performed by varying six properties individually over a representative range. According to these results, the phenomenon of water coning in Tarim fractured sandstone gas reservoirs was explained.

\section{Mathematical model}

There are various mathematical models used to different conditions in the Eclipse software. According to the fractured sandstone gas reservoir data of the A-Well in Dina gas field $\left(K_{\mathrm{m}}<<K_{\mathrm{f}}\right)$, the mathematical model of simulation chosen is as follows.

The water component equation:

$\nabla\left[\frac{K K_{\mathrm{rw}}}{B_{\mathrm{w}} \mu_{\mathrm{w}}} \nabla\left(p_{\mathrm{w}}-\rho_{\mathrm{w}} g D\right)\right]_{\mathrm{f}}+q_{\mathrm{w}}+\tau_{\mathrm{mfw}}=\frac{\partial}{\partial t}\left(\frac{\varphi S_{\mathrm{w}}}{B_{\mathrm{w}}}\right)_{\mathrm{f}}$

The gas component equation:

$\nabla\left[\frac{K K_{\mathrm{rg}}}{B_{\mathrm{g}} \mu_{\mathrm{g}}} \nabla\left(p_{\mathrm{g}}-\rho_{\mathrm{g}} g D\right)\right]_{\mathrm{f}}+q_{\mathrm{g}}+\tau_{\mathrm{mfg}}=\frac{\partial}{\partial t}\left(\frac{\varphi S_{\mathrm{g}}}{B_{\mathrm{g}}}\right)_{\mathrm{f}}$

where $K$ is absolute permeability; $K_{\mathrm{rw}}$ and $K_{\mathrm{rg}}$ are relative permeability to water and gas, respectively; $B_{\mathrm{w}}$ and $B_{\mathrm{g}}$ are water and gas formation volume factor, respectively; $\mu_{\mathrm{w}}$ and $\mu_{\mathrm{g}}$ are water and gas viscosity, respectively; $p_{\mathrm{w}}$ and $p_{\mathrm{g}}$ are water and gas phase pressure, respectively; $\rho_{\mathrm{w}}$ and $\rho_{\mathrm{g}}$ are water and gas density, respectively; $g$ is acceleration of gravity; $D$ is reservoir depth; $\nabla$ denotes gradient vector; $q_{\mathrm{w}}$ and $q_{\mathrm{g}}$ are water and gas source term, respectively; $-\tau_{\mathrm{mfw}}$ and $-\tau_{\mathrm{mfg}}$ are transfer water and gas equation from matrix and fracture, respectively, $-\tau_{\mathrm{mfw}}=\frac{\partial}{\partial t}\left(\frac{\varphi S_{\mathrm{w}}}{B_{\mathrm{w}}}\right)_{\mathrm{m}}$ and $-\tau_{\mathrm{mfg}}=\frac{\partial}{\partial t}\left(\frac{\varphi S_{\mathrm{g}}}{B_{\mathrm{g}}}\right)_{\mathrm{m}} ; \varphi$ is effective reservoir porosity; $S_{\mathrm{w}}$ and $S_{\mathrm{g}}$ are water and gas saturation, respectively; subscripts " $\mathrm{f}$ " and "m" denote fracture and matrix, respectively.

\section{Reservoir description and model}

\subsection{Reservoir description}

In the cases where both log and core analysis data were available, the first priority for porosity and permeability determination was given to core analysis. According to types of open-logs run and drilling mud systems, the log-derived porosity was estimated from various petrophysical models. It was found that there was a good agreement between the log-derived porosity and the corresponding core value. The reservoir permeability was estimated from the result of core analysis.

As a result of the study, the sandstone interval of the A-Well in Dina gas fields was subdivided into 20 layers for the geologic model so as to improve the ability of the model to simulate fluid movement, especially water coning behavior.

\subsection{Reservoir model}

After the characterization of the fractured gas reservoir was determined, a gas-water, fractured sandstone gas reservoir simulation model was built to represent a single well with an underlying aquifer, as shown in Fig. 1 and Fig. 2. The numerical model used is a standard, two phases, black oil model. It is fully implicit with simultaneous and direct solution and therefore suitable for coning studies.
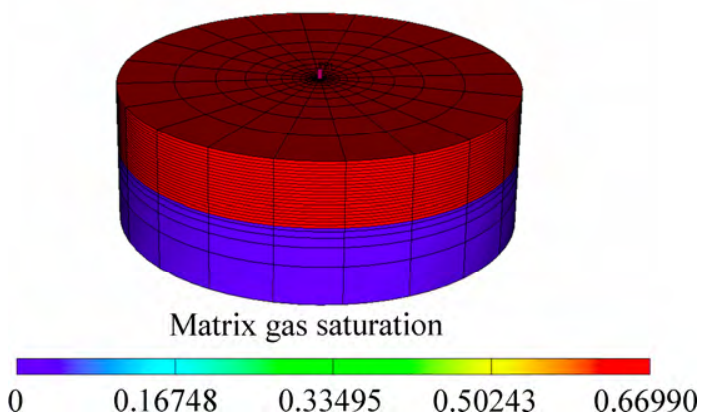

Fig. 1 Three-dimensional simulation model of single well

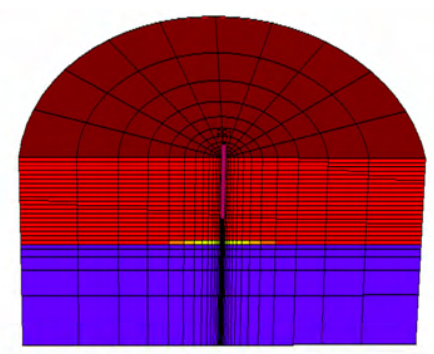

Matrix gas saturation

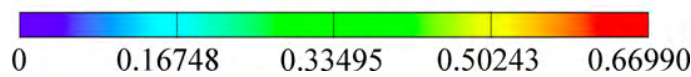

Fig. 2 Cross section model of single well

According to the fractured sandstone gas reservoir data of the A-Well in Dina gas fields chosen, the initial gas-water contact was $100 \mathrm{~m}$ below the top of structure $(5000 \mathrm{~m})$ with a $120 \mathrm{~m}$ underlying aquifer, and the pressure at this depth was $106.5 \mathrm{MPa}$. The base case model properties and operating constraints are summarized in Table 1, Table 2 and Table 3. The simulations were run on the base case, and on models in which parameters were individually varied. 
Table 1 Characteristics of base case of sing-well pattern

\begin{tabular}{|c|c|}
\hline Parameter & Description or value \\
\hline Reservoir model & Dual permeability \\
\hline Griding type & Radial \\
\hline Matrix porosity & 0.11 \\
\hline Fracture porosity & 0.0006 \\
\hline Water compressibility/MPa & $4.08 \times 10^{-5}$ \\
\hline Water permeability/mD & 100 \\
\hline Water thickness/m & 120 \\
\hline Water density $/\left(\mathrm{kg} \cdot \mathrm{m}^{-3}\right)$ & 1100 \\
\hline Gas density $/\left(\mathrm{kg} \cdot \mathrm{m}^{-3}\right)$ & 0.768 \\
\hline Well radius/m & 0.18 \\
\hline Datum depth/m & 5000 \\
\hline Production rate $/\left(\mathrm{m}^{3} \cdot \mathrm{d}^{-1}\right)$ & $4 \times 10^{5}$ \\
\hline Model dimensions & $15 \times 20 \times 50$ \\
\hline Numerical method & FullyImpict \\
\hline Matrix permeability/mD & 1 \\
\hline Fracture permeability/mD & 50 \\
\hline $\begin{array}{l}\text { Water formation volume } \\
\text { factor } /\left(\mathrm{m}^{3} \cdot \mathrm{m}^{-3}\right)\end{array}$ & 1.0224 \\
\hline Water porosity & 0.11 \\
\hline Aquifer type & Bottom drive \\
\hline Oil density $/\left(\mathrm{kg} \cdot \mathrm{m}^{-3}\right)$ & 788.7 \\
\hline Reservoir thickness/m & 100 \\
\hline Reservoir external radius/m & 700 \\
\hline Pressure at datum depth/MPa & 106.2 \\
\hline Perforation depth/m & $70(70 \%)$ \\
\hline
\end{tabular}

Table 2 Pressure-volume-temperature properties of dry gas (No vapourised oil)

\begin{tabular}{ccc}
\hline $\begin{array}{c}\text { Pressure/ } \\
\mathrm{MPa}\end{array}$ & $\begin{array}{c}\text { Gas formation volume } \\
\text { factor } /\left(\mathrm{m}^{3} \cdot \mathrm{m}^{-3}\right)\end{array}$ & $\begin{array}{c}\text { Viscosity/ } \\
\left(10^{-3} \mathrm{~Pa} \cdot \mathrm{s}\right)\end{array}$ \\
\hline 14 & 0.0096 & 0.01654 \\
20 & 0.0068 & 0.01865 \\
28 & 0.0051 & 0.02212 \\
36 & 0.0042 & 0.02591 \\
40 & 0.0039 & 0.02785 \\
50 & 0.0034 & 0.03205 \\
60 & 0.0031 & 0.03575 \\
70 & 0.0028 & 0.0392 \\
106.05 & 0.0024 & 0.05102 \\
\hline
\end{tabular}

\section{Simulation results and discussion}

A parametric study has been conducted to analyze the effect of the most relevant parameters on water coning using the single-well model. They are matrix
Table 3 Gas$^{-}$water relative permeability

\begin{tabular}{ccc}
\hline$S_{\mathrm{w}}$ & $K_{\mathrm{g}}$ & $K_{\mathrm{w}}$ \\
\hline 0.9553 & 0.0036 & 0.8576 \\
0.9107 & 0.0071 & 0.7152 \\
0.866 & 0.011 & 0.5689 \\
0.8213 & 0.0166 & 0.4216 \\
0.7767 & 0.0261 & 0.2882 \\
0.732 & 0.0404 & 0.1848 \\
0.6873 & 0.0607 & 0.1225 \\
0.6427 & 0.0862 & 0.0861 \\
0.598 & 0.1172 & 0.0627 \\
0.5533 & 0.1547 & 0.0466 \\
0.464 & 0.2526 & 0.0239 \\
0.4193 & 0.3142 & 0.0153 \\
0.3747 & 0.3857 & 0.0078 \\
0.33 & 0.4661 & 0 \\
\hline
\end{tabular}

permeability, fracture permeability, vertical-to-horizontal permeability ratio, well penetration, aquifer size and gas production rate. All simulation runs for the single-well model were done for 7-year forecast. Before the formal runs, many computer runs were made with different grid sizes and different time steps to estimate the sensitivity of the numerical results to grid sizes and time steps.

\subsection{Matrix permeability effect}

Matrix permeability is one of the uncontrollable parameters in water coning phenomenon. Five different cases have been selected to study the effect of water coning. The results are shown in Fig. 3 and Fig. 4. With the increase of matrix permeability, the water cut increases from 0.1 to $1 \mathrm{mD}$ and then decreases from 5 to $10 \mathrm{mD}$. And the larger the matrix permeability is, the higher the recovery factor is. This is due to higher production from the matrix in the transition zone with increasing the matrix permeability, thus the ultimate recovery factor is relatively higher.

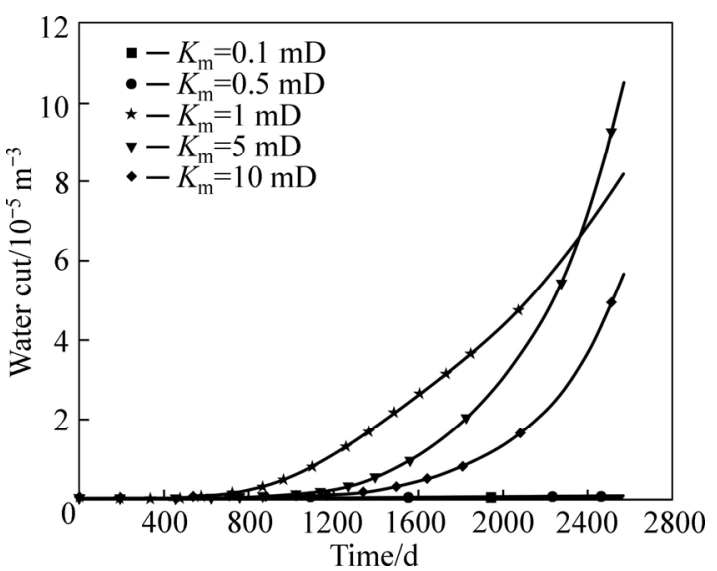

Fig. 3 Water cut versus time for different matrix permeabilities 


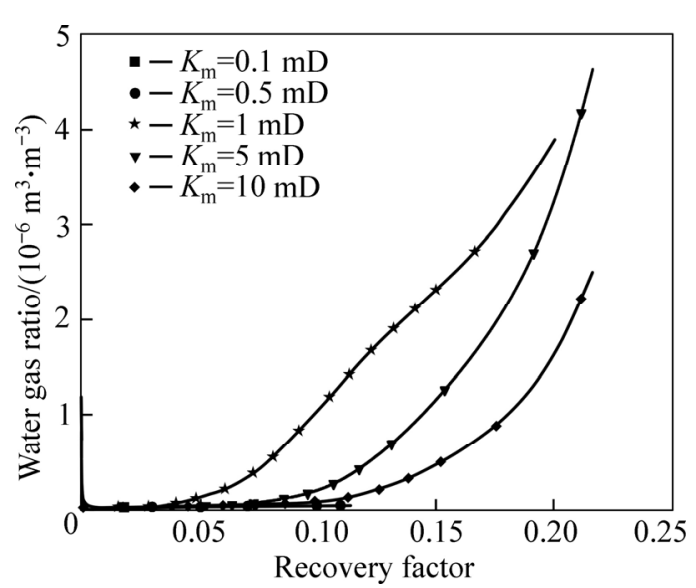

Fig. 4 Water gas ratio versus recovery factor for different matrix permeabilities

\subsection{Fracture permeability effect}

Fracture permeability is the most important uncontrollable parameter in water coning, because water cone front in fractures moves faster than matrixes in the fractured gas reservoirs. Five cases with different fracture permeabilities from 10 to $500 \mathrm{mD}$ were selected. Figure 5 shows water cut versus time, and Fig. 6 depicts

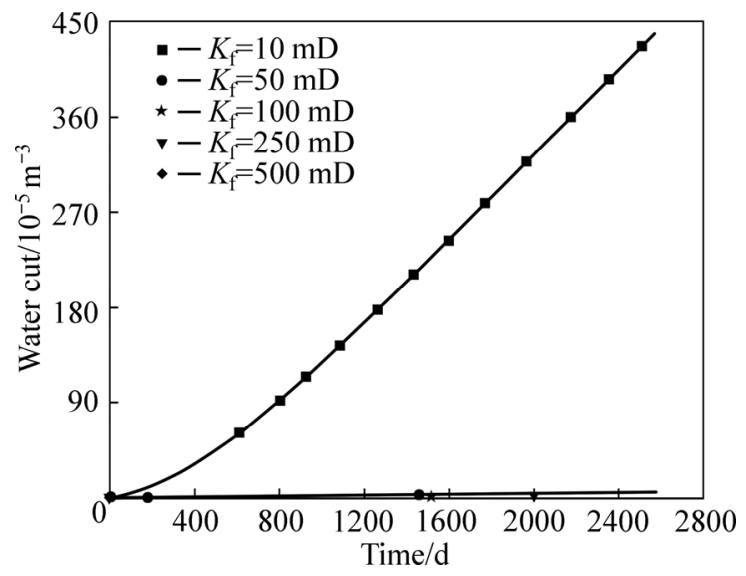

Fig. 5 Water cut versus time for different fracture permeabilities

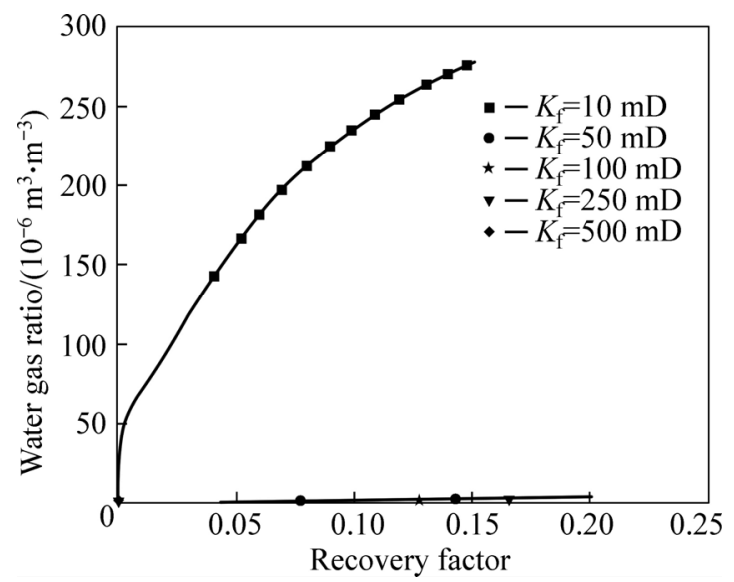

Fig. 6 Water gas ratio versus recovery factor for different fracture permeabilities water gas ratio versus recovery factor. As we can observe, with the fracture permeability increasing, water cut is significantly lower and breakthrough is quite late, hence the recovery factor is relatively higher. Although the result may be counter-intuitive, the well operates with a rate constraint for its production. The pressure gradients are smaller with the higher permeability, thus water coning is reduced. Since most of the production comes from the fractures, this effect is not observed upon increasing matrix permeability.

\subsection{Vertical-to-horizontal permeability ratio effect}

Five cases with different vertical-to-horizontal permeability ratios from 0.1 to 500 are selected to study the water coning phenomenon, as shown in Fig. 7 and Fig. 8. As the vertical-to-horizontal permeability ratio increases, there is a significant rise in water cut and the breakthrough time is early, thus recovery factor is correspondingly reduced. This is because that the higher ratio of vertical-to-horizontal permeability is conducive to the coning tendency. Namely, the higher the verticalto-horizontal permeability ratio is, the faster the vertical flow is.

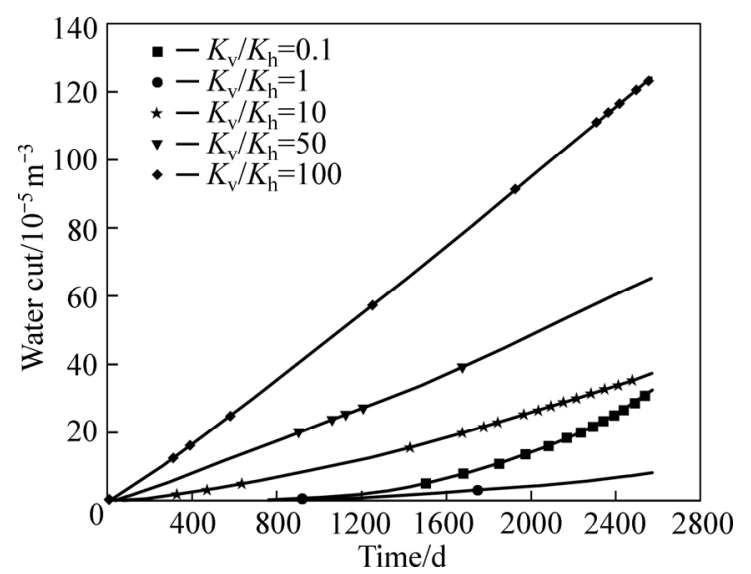

Fig. 7 Water cut versus time for different vertical-to-horizontal permeability ratios

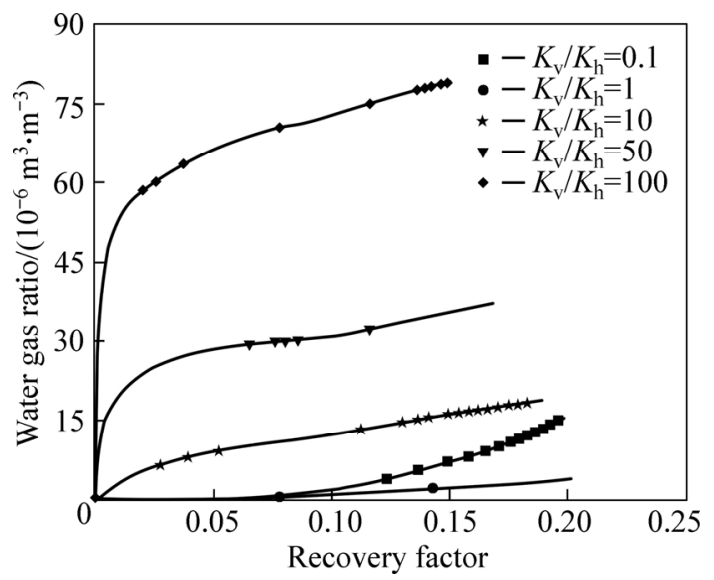

Fig. 8 Water gas ratio versus recovery factor for different vertical-to-horizontal permeability ratios 


\subsection{Well penetration effect}

The extent of well penetration into the pay thickness has a considerable effect on water coning and water breakthrough time. Five cases with different well penetrations from $20 \%$ to $70 \%$ have been selected while the total gas pay thickness was constant. The results are shown in Fig. 9 and Fig. 10. From the results, the larger the extent of well penetration is, the higher the water cut is and the earlier the breakthrough time is, while the higher the recovery factor is. The reason is that the reservoir physics performs well, and it is also related to gas property.

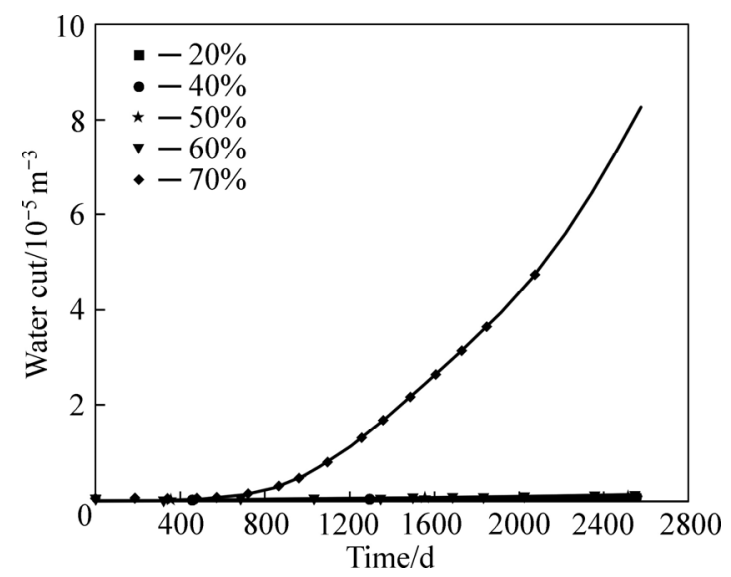

Fig. 9 Water cut versus time for different well penetrations

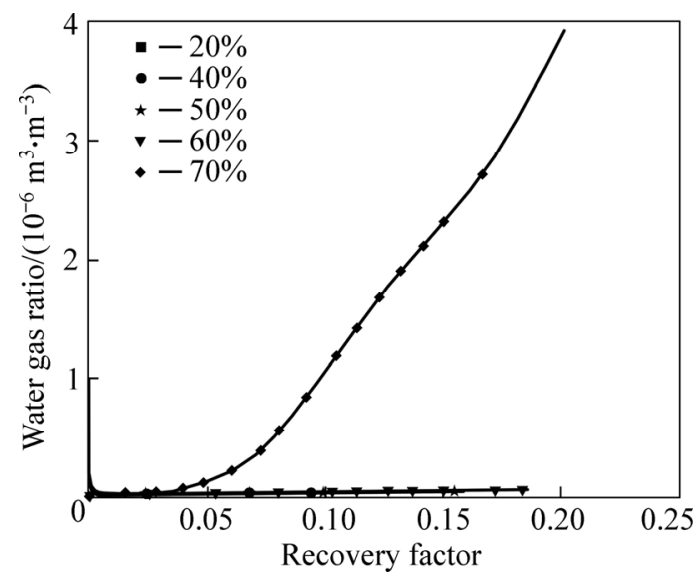

Fig. 10 Water gas ratio versus recovery factor for different well penetrations

\subsection{Aquifer size effect}

Aquifer size is one of the uncontrollable parameters in water coning. Five cases with different aquifer sizes have been modeled. The aquifer size is varied from 60 to $480 \mathrm{~m}$. From the results of Fig. 11 and Fig. 12, the recovery factor is essentially unchanged while the water cut and water gas ratio increase with aquifer size. The result is reasonable since the larger aquifer increases the expansion force driving the water upwards. However, as the gas-in-place and residual saturations are unchanged, the ultimate recovery factor is unaffected by the increased water cut.

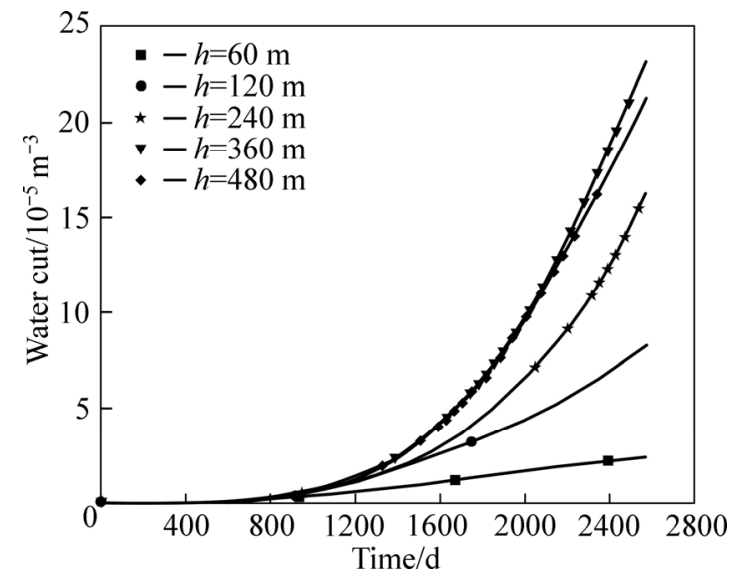

Fig. 11 Water cut versus time for different aquifer sizes

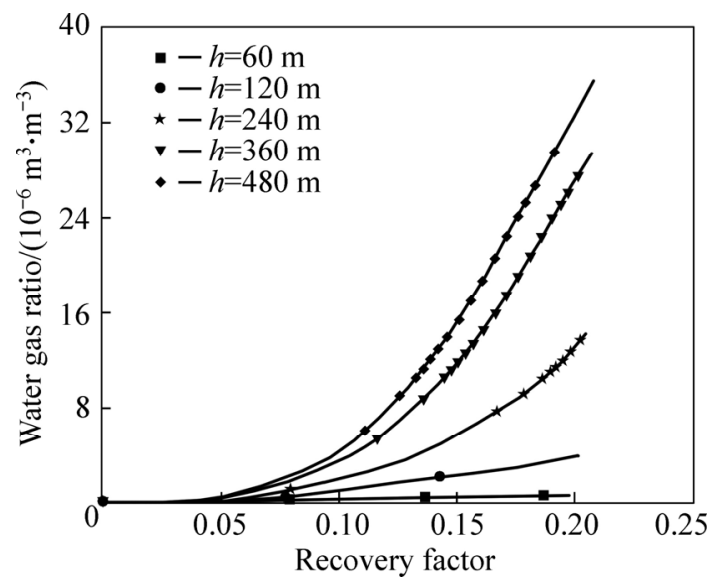

Fig. 12 Water gas ratio versus recovery factor for different aquifer sizes

\subsection{Gas production rate effect}

The most controllable parameter in water coning phenomenon is gas production rate. Five cases with different gas production rates have been selected to study water coning. The gas production rate is varied from $2 \times 10^{5}$ to $6 \times 10^{5} \mathrm{~m}^{3} / \mathrm{d}$. As shown in Fig. 13 and Fig. 14, the reduced gas production rates cause relatively lower water cut and later breakthrough while the ultimate recovery is lower. Most of the wells have high

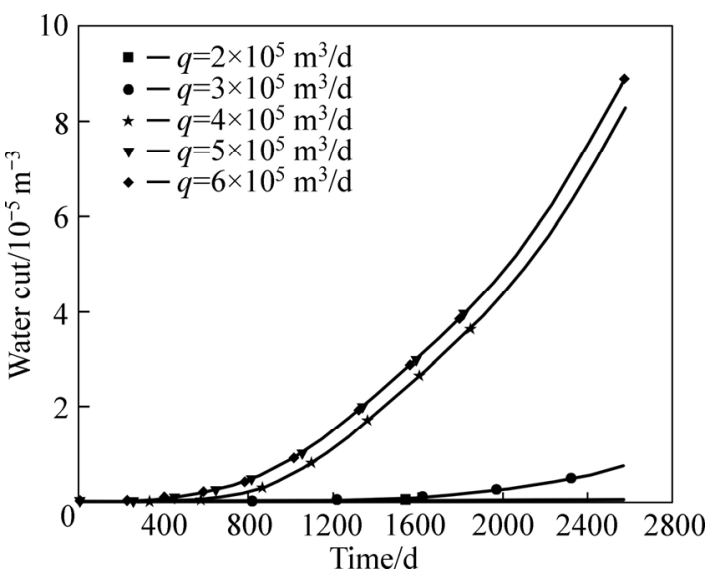

Fig. 13 Water cut versus time for different gas production rates 


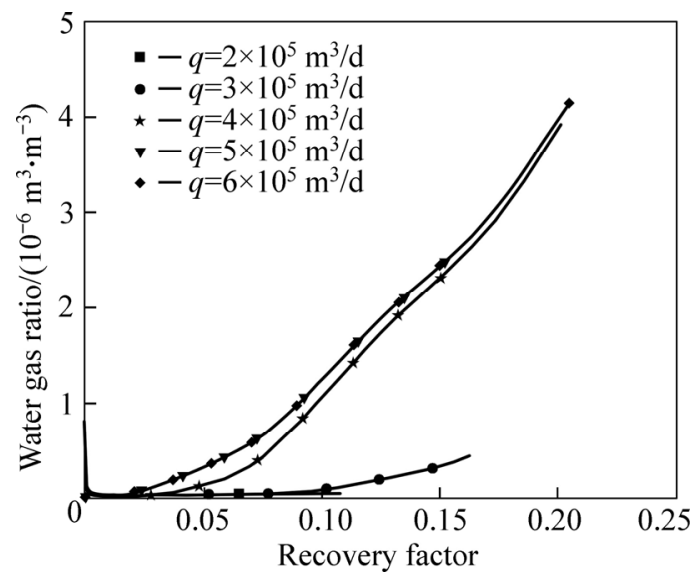

Fig. 14 Water gas ratio versus recovery factor for different gas production rates

productivity and can produce at high rates in the fractured gas reservoirs, and the critical rate is very lower, which is not economical to produce. Therefore, the optimization of gas production rate is essential for controlling of water coning problem by considering the most profitable long-term economical conditions in the fractured gas reservoirs.

\section{Conclusions}

1) Matrix permeability, well penetration especially fracture permeability, vertical-to-horizontal permeability ratio, aquifer size and gas production rate have considerable effect on water coning in the fractured gas reservoirs.

2) With increasing the fracture permeability, water cut is significantly low and breakthrough is quite late. The reason is that the well operates with a rate constraint for its production. And the pressure gradients are smaller with the higher permeability, thus water coning is reduced.

3) The larger the vertical-to-horizontal permeability ratio is, the larger the water cut is and the lower the recovery factor is. The larger the aquifer size is, the higher the water cut is and the lower the recovery is.

4) The lower the gas production rate is, the lower the water cut is and the lower the ultimate recovery is. Thus, the optimization of gas production rate is essential for controlling of water coning problem by considering the most profitable long-term economical conditions since most of the wells have high productivity and can produce at high rates in the fractured gas reservoirs.

5) Investigation of effective parameters is necessary to understand the mechanism of water coning phenomenon. Simulation of the problem helps to optimize the conditions in which the breakthrough time of water coning is delayed.

\section{References}

[1] SAAD S M, DARWICH T D, ASSAD Y. Water coning in fractured basement reservoirs [C]// Middle East Oil Show. Bahrain: SPE, 1995: 144-161.

[2] OULD-AMER Y, CHIKH S. Transient behavior of water-oil interface in an upward flow in porous media [J]. Journal of Porous Media, 2003, 6(2): 1-12.

[3] OULD-AMER Y, CHIKH S, NAJI H. Attenuation of water coning using dual completion technology [J]. Journal of Petroleum Science and Engineering, 2004, 45: 109-122.

[4] SHEN Wei-jun, LI Xi-zhe, LIU Xiao-hua, LU Jia-liang. The calculating method of reasonable producing pressure drop in gas reservoirs with bottom water $[\mathrm{C}] / /$ Advance and Challenges on Fluid Flow in Porous Media-Proceedings of the 12th National Conference on Fluid Flow in Porous Media. Qingdao: China University of Petroleum Press, 2013: 225-227. (in Chinese)

[5] LI Xi-zhe, WANG Yu-jin, LU Jia-liang. Complex gas reservoir development technology $[\mathrm{M}]$. Beijing: Petroleum Industry Press, 2010: 44-61. (in Chinese)

[6] MUSKAT M, WYCOFF R D. An approximate theory of water coning in oil production [J]. Trans AIME, 1935, 114: 144-161.

[7] MENOUAL H K, HAKIM A A. Water coning and critical rates in vertical and horizontal wells $[\mathrm{C}] / /$ Middle East Oil Show. Bahrain: SPE, 1995: 367-379.

[8] SHADIZADEH S R, GHORBANI D. Investigation of water/gas coning in natural fractured hydrocarbon reservoirs $[\mathrm{C}] / /$ Canadian International Petroleum Conference. Calgary: SPE, 2001: 1-5.

[9] JIN L, WOJTANOWICZ A K, HUGHES R G. Analytical model for water coning control installation in reservoir with bottom water [J]. Journal of Canadian Petroleum Technology, 2010, 49(5): 65-70.

[10] PEREZ E, RODRIGUEZ F, SAMANIEGO F. Water coning in naturally fractured carbonate heavy oil reservoir-a simulation study $[C] / /$ SPE Latin America and Caribbean Petroleum Engineering Conference. Mexico: SPE, 2012: 1-15.

[11] AMARFIO E M, LGBOKOYI A O. Breakthrough time correlations for coning in bottom water supported reservoirs [C]// 2013 SPE Eastern Regional Meeting. Pittsburgh: SPE, 2013: 1-10.

[12] ECHAM R R, OSISANYA S O, TOUAMI M. Effects of water coning on the performance of vertical and horizontal wells-A reservoir simulation study of Hassi R'mel Field, Algeria [C]// SPE/PS-CIM International Conference on Horizontal Well Technology. Calgary: SPE, 2000: 1-12.

[13] NAMANI M, ASADOLLAHI M, HAGHIGHI M. Investigation of water-Coning phenomenon in Iranian carbonate fractured reservoirs [C]// International Oil Conference and Exhibition in Mexico. Veracruz: SPE, 2007: 1-11.

[14] SHAHBAZ M, KEVIN M, JULIO S. The effect of bottom water coning and its monitoring for optimization in SAGD [C]// SPE Heavy Oil Conference Canada. Calgary: SPE, 2012: 1-12.

[15] KABIR C S. Predicting gas well performance coning water in bottom water drive reservoirs $[\mathrm{C}] / /$ SPE Annual Technical Conference and Exhibition. San Francisco: SPE, 1983: 1-15.

[16] HAMON G, MAUDUIT D, BANDIZIOL D. Recovery optimization in a naturally fractured water-drive gas reservoir: Mellion field $[\mathrm{C}] / /$ SPE Annual Technical Conference and Exhibition. Dallas: SPE, 1991: 1-16.

[17] VAN T D, SONIER F. Water-coning in a fractured Reservoir [C]// SPE Annual Technical Conference and Exhibition. New Orleans: SPE, 1994: 1-15.

[18] SUN Long-de, SONG Wen-jie, JIANG Tong-wen. Oil and gas exploration and development in Tarim basin and the resource of west-to-east pipeline project [C]// 18th World Petroleum Congress. Johannesburg: SPE, 2005: 1-9. 